\title{
Profiling Sulfur(VI) Fluorides as Reactive Functionalities for Chemical Bi- ology Tools and Expansion of the Ligandable Proteome
}

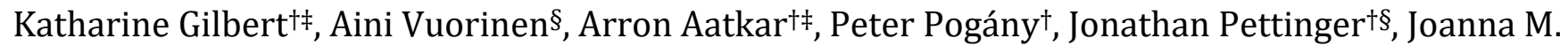 \\ Kirkpatrick", Katrin Rittinger", David House†§, Glenn A. Burley‡, Jacob T. Bush ${ }^{\dagger *}$. \\ †GlaxoSmithKline, Gunnels Wood Road, Stevenage, Hertfordshire, SG1 2NY, United Kingdom. \#University of Strathclyde, \\ 295 Cathedral Street, Glasgow, G11XL, United Kingdom. §Crick-GSK Biomedical LinkLabs, GlaxoSmithKline, Gunnels \\ Wood Road, Stevenage SG1 2NY, United Kingdom. "The Francis Crick Institute, 1 Midland Road, London, NW1 1AT, \\ United Kingdom.
}

\begin{abstract}
Chemical probes are valuable tools to explore the function of proteins. Incorporation of electrophiles into small molecules enables covalent capture of protein interactions and provides access to powerful technologies including chemoproteomic profiling and reactive fragment screening. Current approaches have been largely limited to protein pockets containing cysteine, so establishing strategies to target other amino acid residues is essential to expanding the applicability across the proteome. Here, we profiled sulfur(VI) fluorides ( $\left.\mathrm{S}^{\mathrm{VI}}-\mathrm{F}\right)$ as reactive functionalities that can modify multiple residues including Lys, Tyr, His and Ser, thus offering utility for targeting almost any protein. These studies provided an in-depth understanding of S SI-F functionalities, including hydrolytic stability, protein reactivity and utility in chemoproteomics. Such insights offer a valuable guide for the prospective design of $\mathrm{S}^{\mathrm{VI}}$-F-containing ligands for various chemical biology workflows and illustrate the wide range of proteins that $\mathrm{S}^{\mathrm{VI}}$-Fs can capture, thus highlighting the opportunity for $\mathrm{S}^{\mathrm{VI}}$-Fs to expand the liganded proteome.
\end{abstract}

\section{INTRODUCTION}

Chemical probes offer a molecular toolkit for the study of the proteome and validation of potential therapeutic targets. ${ }^{1}$ Probes that bear reactive functionalities have proved particularly powerful for the study of protein targets through the covalent modification of selected amino acids. ${ }^{2,3}$ Covalent inhibitors and therapeutics provide a proven strategy to enhance potency and selectivity, and reduce dosing frequency (Figure 1Ai). ${ }^{4-7}$ Reactive tools have also been employed broadly in chemical biology, enabling robust protein capture and providing access to a suite of techniques, including chemoproteomic mapping of ligand-protein interactions across the proteome (Figure 1Aii)..$^{8,9}$ More recently, reactive fragment-based screening platforms have been developed for streamlined and robust detection of hits, both with purified proteins of interest and in proteome-wide screening, which offers a route to expand the liganded proteome (Figure 1Aiii). ${ }^{10-16}$

Existing reactive approaches have traditionally utilised cysteine-targeting electrophiles, exploiting the enhanced nucleophilicity of these residues to enable quantitative modification, and often inhibition, of target proteins (Figure 1Bi). ${ }^{17-19}$ There are, however, a limited number of protein pockets that contain an accessible cysteine. Whilst photoreactive functionalities can provide improved proteome coverage by potentially modifying any residue, the low levels of modification can limit their sensitivity (Figure 1Bii). ${ }^{20-22} \mathrm{Re}-$ active functionalities that enable robust, high-yielding covalent capture of an expanded set of amino acid residues will diversify the proteome that can be targeted by covalent tools.
Sulfur(VI) fluorides ( $\mathrm{S}^{\mathrm{VI}}-\mathrm{F}$ ) have emerged as a promising electrophilic group for the covalent modification of proteins, reacting with multiple nucleophilic amino acid residues including Tyr, Lys, His, Arg, Ser and Thr (Figure 1Biii).

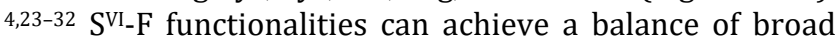
protein reactivity alongside high yields of modification. Therefore, $\mathrm{S}^{\mathrm{VI}}$-F electrophiles present an opportunity to extend the technologies offered by cysteine-electrophilic strategies to a considerably broader range of protein targets. Despite their potential both in drug discovery and as chemical biology tools, a consolidated and strategic approach to tuning $\mathrm{S}^{\mathrm{VI}}$-F reactivity is currently lacking. Multiple factors must be considered for incorporation of $\mathrm{S}^{\mathrm{VI}} \mathrm{F}$ electrophiles, including susceptibility to competing hydrolysis, reactivity with target proteins, and proteome-wide promiscuity. ${ }^{33}$ A thorough understanding of S ${ }^{\mathrm{VI}}$-F reactivity in the context of chemical biology and drug discovery workflows is therefore crucial to the optimal application of these functionalities.

Herein, we present a series of detailed studies on S $\mathrm{SI}_{-} \mathrm{F}$ electrophiles in the context of hydrolytic stability and reactivity, protein modification, and proteome-wide reactivity in live cells (Figure 1C). This profiling workflow revealed that $\mathrm{S}^{\mathrm{VI}} \mathrm{F}$ electrophiles exhibit diverse, yet tuneable reactivity across these systems, providing rich insights to guide the strategic design of $\mathrm{S}^{\mathrm{VI}}$-F reactive tools. 
i. Therapeutics

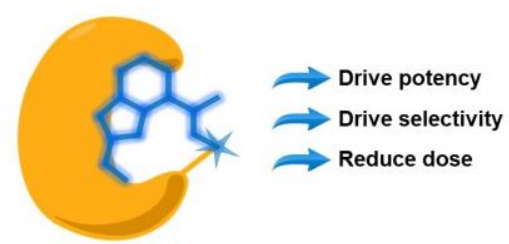

ii. Chemoproteomic profiling

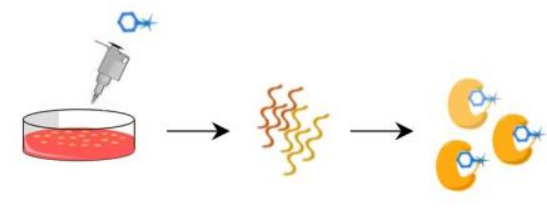

iii. Fragment screening

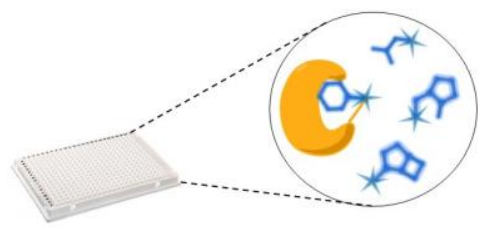

\section{B. Reactive functionalities}

\section{i. Cysteine-targeting}

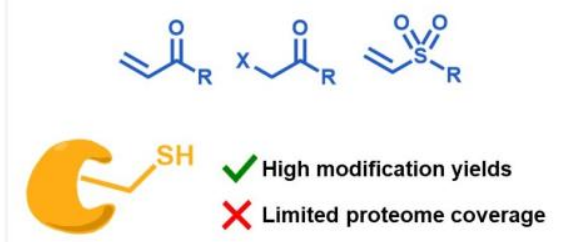

ii. Photoreactive

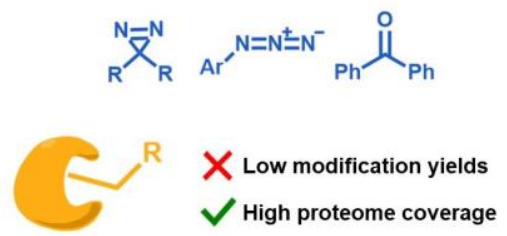

iii. Sulfur(VI) fluoride

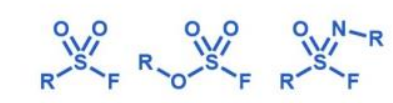

C. This work: Profiling sulfur(VI) fluoride electrophiles to enable optimal application in chemical biology

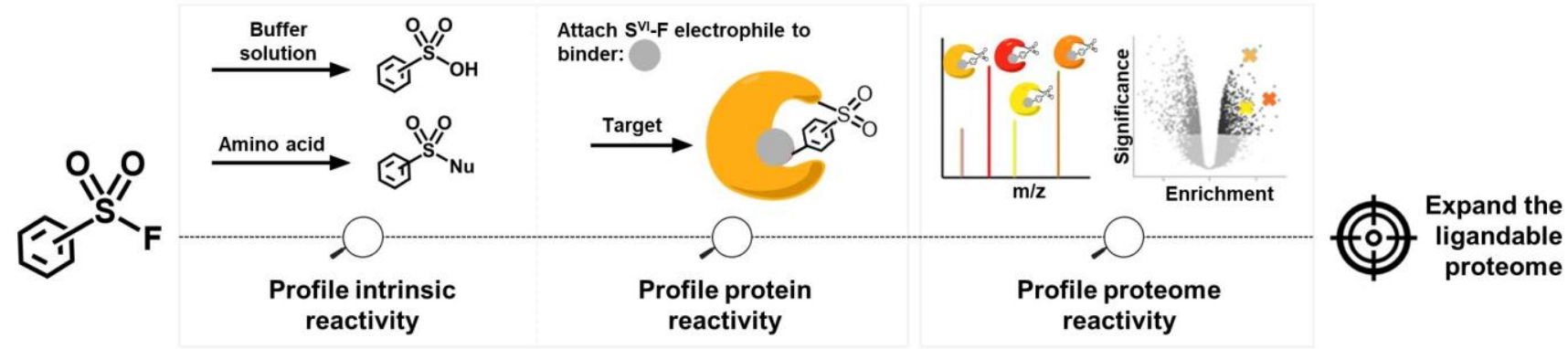

Figure 1. A) Reactive functionalities hold valuable application in i. covalent drugs for reduced dosing, ii. chemoproteomic profiling to assess global target engagement, and iii. fragment screening to detect transient fragment-protein interactions. B) SVI-Fs offer utility beyond other functionalities typically employed in chemical biology by modifying with high efficiency (cf. Cys-reactive) and broadening proteome coverage (cf. photoreactive). C) This work: profiling SVI-F electrophiles, which will enable their knowledgeguided design for optimal chemical biology application.

\section{RESULTS AND DISCUSSION}

To explore the opportunity to use SVI-F electrophiles as tools in chemical biology, we designed a panel of nine $\mathrm{S}^{\mathrm{VI}}$-F electrophiles (a-i) (Figure 2A). The SVI-F electrophiles contained a carboxylic acid or sulfonyl chloride functionality for conjugation with privileged scaffolds to build reactive tools. Primarily aryl S ${ }^{\mathrm{VI}}$-Fs were selected on the basis of their hydrolytic stability compared to aliphatic analogues, which typically undergo facile elimination via a sulfene intermediate. ${ }^{34}$ Heteroatom-linked S SI-F functionalities were also included, e.g. fluorosulfate (g) and sulfamoyl fluoride (i). The set included a range of electron-withdrawing and electron-donating substituents to assess the influence of electronics on reactivity and consisted of multiple matched pairs to enable the investigation of point electronic changes upon intrinsic reactivity.

Stability, reactivity and biochemical protein modification. Hydrolytic stability and target reactivity are key parameters in determining the suitability of an electrophile for application in biochemical and cellular studies. We first investigated both the hydrolytic stability of SVI-F electrophiles and the reactivity towards amino acids using a morpholine ring as a representative building block of a drug-like molecule. $\mathrm{S}^{\mathrm{VI}}$-F electrophiles (a-i) were coupled to morpholine by nucleophilic substitution chemistry or HATUmediated amide couplings to furnish the $\mathrm{S}^{\mathrm{VI}}$-F fragment panel 1a-i.

The hydrolytic stability of $\mathrm{S}^{\mathrm{VI}}$-F fragments $\mathbf{1 a}-\mathbf{i}$ was investigated by incubation with PBS and HEPES buffers at pH 7 and 8 to span the physiological $\mathrm{pH}$ range. An additional experiment was undertaken in carbonate-bicarbonate buffer at $\mathrm{pH} 10$ to further differentiate $\mathrm{S}^{\mathrm{VI}}-\mathrm{F}$ reactivity. Rates and half-lives of hydrolysis were determined by monitoring the depletion of $\mathrm{S}^{\mathrm{VI}}$-F fragments using HPLC (Figure 2B).

$\mathrm{S}^{\mathrm{VI}}$-F fragments 1a-i exhibited a considerable range of aqueous stabilities, with measured half-lives from 35 minutes to 
C

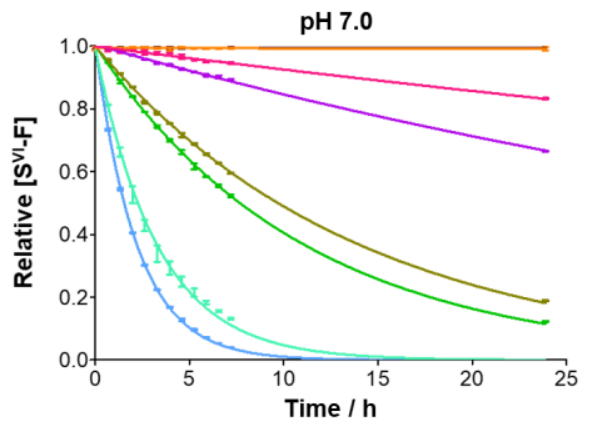

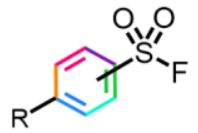

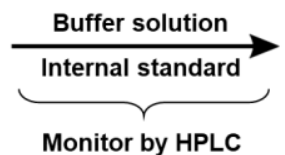

Monitor by HPLC

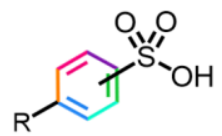

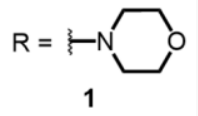

1
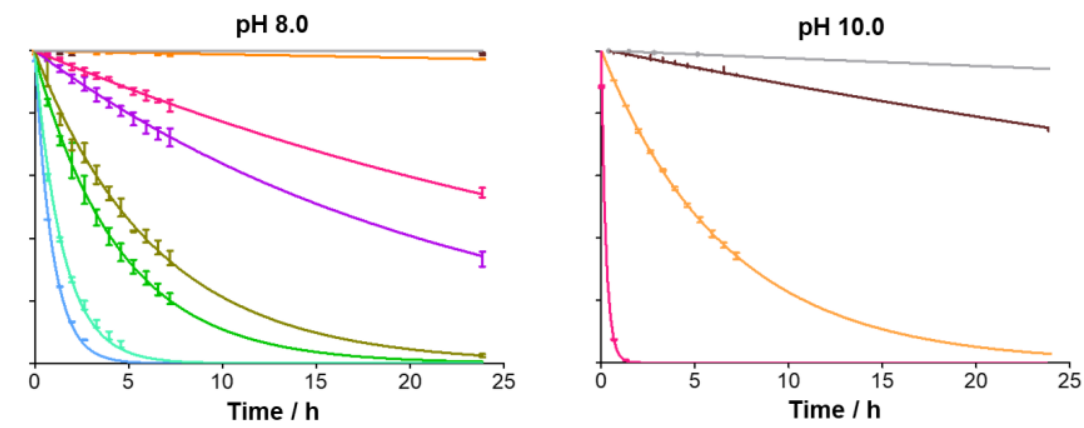

D

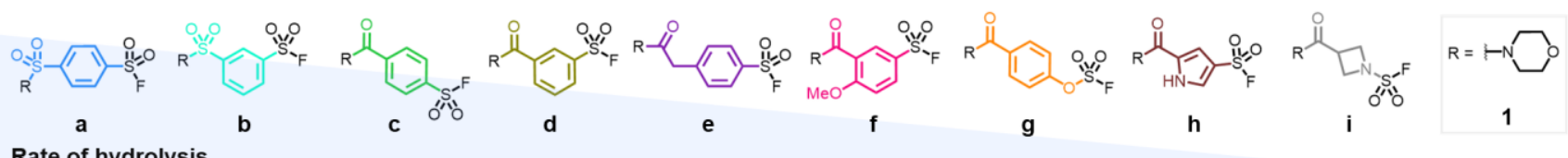

Rate of hydrolysis

E

\begin{tabular}{|c|c|c|c|c|c|c|c|c|c|c|}
\hline & & $1 a$ & $1 b$ & 1c & 1d & $1 e$ & $1 \mathrm{f}$ & $1 \mathrm{~g}$ & $1 \mathrm{~h}$ & $1 \mathrm{i}$ \\
\hline & $\begin{array}{l}\text { PBS buffer, } \\
\text { pH } 7\end{array}$ & 1.5 & 2.3 & 7.6 & 9.7 & 40.5 & 90.3 & 1700 & $\begin{array}{l}>1700 \\
\left(4700^{\circ}\right)\end{array}$ & $\begin{array}{c}>1700 \\
\left(1.84 \times 10^{6^{*}}\right)\end{array}$ \\
\hline \multirow[t]{3}{*}{$\begin{array}{l}\text { Half } \\
\text {-life } \\
/ \mathrm{h}\end{array}$} & $\begin{array}{l}\text { PBS buffer, } \\
\text { pH } 8\end{array}$ & 0.6 & 1.0 & 3.1 & 4.3 & 15.3 & 26.9 & 612 & $\begin{array}{c}>612 \\
\left(1510^{\circ}\right)\end{array}$ & $\begin{array}{c}>612 \\
\left(4.87 \times 10^{5^{*}}\right)\end{array}$ \\
\hline & $\begin{array}{l}\text { Bicarbonate } \\
\text { buffer, } \\
\text { pH } 10\end{array}$ & $<0.2$ & $<0.2$ & $<0.2$ & $<0.2$ & $<0.2$ & 0.2 & 4.7 & 55.6 & 272 \\
\hline & E(LUMO) & -0.092 & -0.085 & -0.080 & -0.077 & -0.073 & -0.066 & -0.055 & -0.049 & -0.019 \\
\hline
\end{tabular}

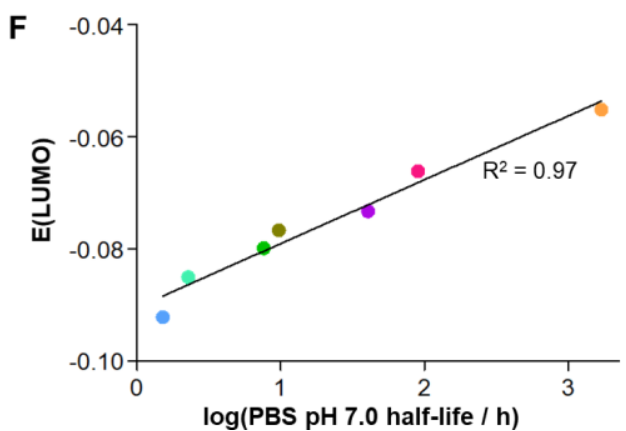

Figure 2. A) The general structure of SVI-F electrophiles (a-i). B) Aqueous stability measurements using morpholine-substituted SVI-Fs 1a-i. C) The hydrolytic stability profile of SVI-Fs 1a-i under various buffer conditions. Line colours correspond to the SVI-F electrophiles in Figure 2D. D) The structures of fragments 1a-i ordered by their rates of hydrolysis in buffer solutions. E) The calculated LUMO energies and experimentally measured half-lives of 1a-i in aqueous buffer solution. * Half-lives predicted using LUMO energy models. F) The correlation of calculated LUMO energies with measured aqueous half-lives $\left(\mathrm{R}^{2}=0.97\right)$.

$>600$ hours (Figure 2C-E, SI Figure 1-6, SI Table 1). Hydrolysis rates were accelerated under basic conditions, with half-lives at $\mathrm{pH} 8$ approximately twofold lower than at $\mathrm{pH} 7$ (PBS buffer) and dramatically reduced at pH 10 (carbonate-bicarbonate buffer). Hydrolytic stability was approximately twofold greater in HEPES vs PBS buffer for all fragments at $\mathrm{pH} 7$ and 8, indicating an influence of buffer identity on $\mathrm{S}^{\mathrm{VI}}$-F stability. Aqueous stability of the fragments was found to be independent of $\mathrm{NaCl}$ concentration.

The order of intrinsic reactivity of $\mathbf{1 a}-\mathbf{i}$ correlated well with the electronic factors that influence the electrophilicity of the sulfur centre. Para-amide and -sulfonamide S ${ }^{\mathrm{VI}}$-F electrophiles hydrolysed faster than the meta analogues (1a vs $\mathbf{1 b}, \mathbf{1 c}$ vs 1d). Substituents that increased the electron-density on the phenyl ring imparted marked stabilisation, as observed with the addition of a methylene spacer (1e vs 1c) and para-methoxy moiety (1f vs $\mathbf{1 d}$ ). The fluorosulfate $\mathbf{1 g}$, pyrrole $\mathbf{1 h}$, and N-linked S ${ }^{\mathrm{VI}}$-F electrophile $\mathbf{1 i}$ displayed the greatest stability, undergoing negligible hydrolysis over 24 hours at pH 8. The experiment performed at pH 10 (bicarbonate buffer) revealed reactivities in the order fluorosulfate $\mathbf{1} \mathbf{g}>$ pyrrole $\mathbf{1 h}>$ sulfamoyl fluoride $\mathbf{1 i}$.

It was anticipated that methods for the prediction of hydrolytic stability would be valuable to guide the design of novel $\mathrm{S}^{\mathrm{VI}}$-F reactive tools. Hence, energy calculations were performed to determine whether a correlation exists between hydrolytic reactivity and LUMO energy. Three quantum mechanical approaches were employed. First, a semiempirical method was used (AM1), which gave poor correlation with the half-lives of SVI-Fs $1 \mathbf{1 a}-\mathbf{i}\left(\mathrm{R}^{2}=0.31\right) \cdot{ }^{35}$ Subsequently, two higher level DFT methods were employed to improve accuracy; B3LYP-D3 with 6-31+G** and B3LYP-D3 with aug-ccPVTZ, which provided the best accuracy. ${ }^{36,37}$ LUMO energies 
A

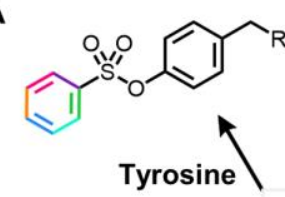

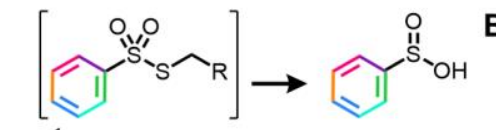

Cysteine
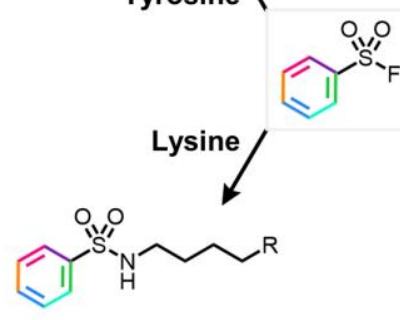

$$
\text { cosstos }
$$

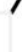

\section{(5)}

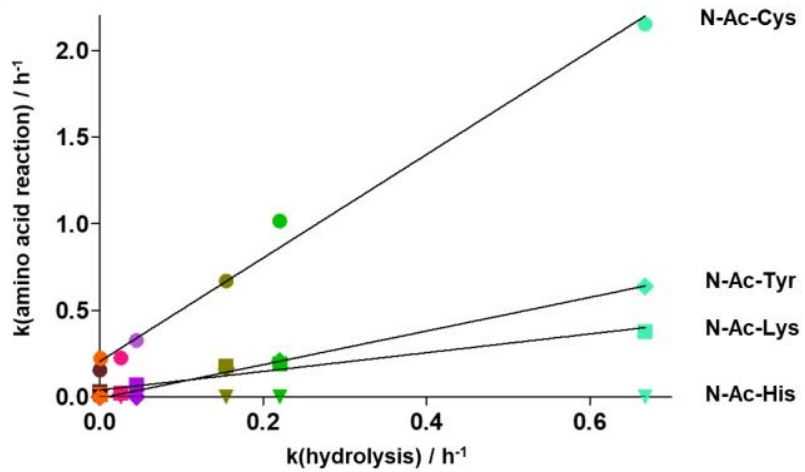

C

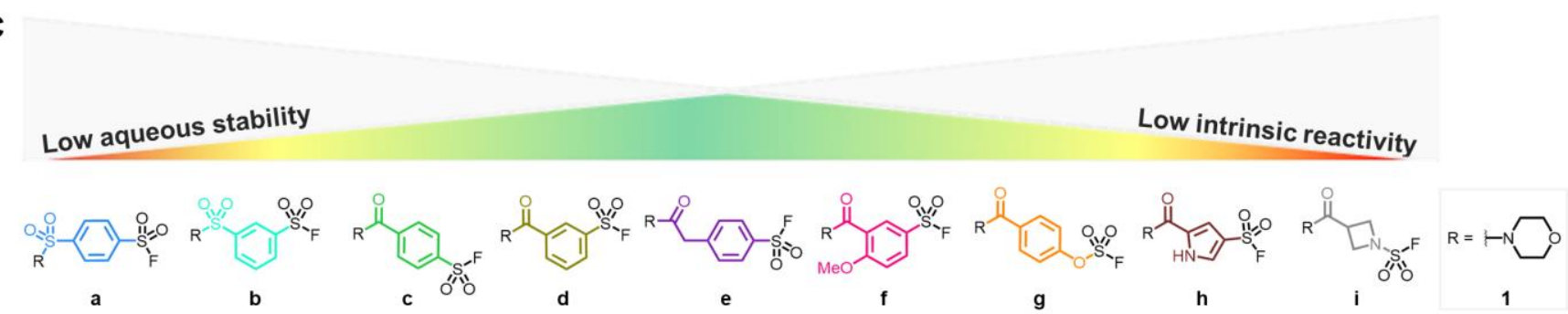

Figure 3. A) Amino acid adducts formed with SVI-F fragments and nucleophilic amino acids. B) The correlation between rate constants for hydrolysis and for reaction with $\mathrm{N}$-acyl-protected nucleophilic amino acids in PBS buffer at $\mathrm{pH}$ 8.0. The rate of reaction of fragment 1a with amino acids was too high for accurate rate constant measurement. C) SVI-F electrophiles will ideally possess a balance between aqueous stability and intrinsic reactivity: (d-f).

directly correlated with the aqueous half-lives of S $\mathrm{VI}_{-} \mathrm{F}$ electrophiles 1a-i $\left(\mathrm{R}^{2}=0.97\right)$ (Figure $2 \mathrm{~F}$ ). This relationship provides the basis for prospective design of SVI-F modalities that occupy the desired reactivity space, enabling the prioritisation of $\mathrm{S}^{\mathrm{VI}}-\mathrm{F}$ compounds for synthesis as reactive chemical probes.

Hydrolytic stability has provided key insight into the behaviour of $\mathrm{S}^{\mathrm{VI}}-\mathrm{F}$ functionalities, though a balance must be achieved with amino acid reactivity to ensure that protein modification occurs at an appropriate rate. $\mathrm{S}^{\mathrm{VI}}$-F electrophiles have been reported to react with Lys, Tyr and His residues to form stable covalent adducts. While the nucleophilicity and $\mathrm{pK}_{\mathrm{a}}$ of amino acid residues is known to be perturbed in protein environments, we initially studied the reactivity of the SVI-F electrophiles with individual amino acids to establish benchmarking data. ${ }^{33}$ We initially studied the reactivity of $\mathbf{1 a}-\mathbf{i}$ with monomeric amino acids: $N$-acetyltyrosine, $N_{\alpha}$-acetyllysine, $N$-acetylhistidine and $\mathrm{N}$-acetylcysteine (Figure 3A, SI Figure 6). Reaction rates were monitored by HPLC and fit using pseudo-first order kinetics, as established by the 10 -fold excess of amino acid. ${ }^{38}$

The reactivity of fragments $\mathbf{1 a}-\mathbf{i}$ with the amino acids was found to closely correlate with the rate of hydrolysis (Figure 3B). This correlation indicated that there was no opportunity within this set of S $\mathrm{VI}^{\mathrm{V}} \mathrm{F}$ electrophiles, to tailor an S $\mathrm{VI}_{-} \mathrm{F}$ for preferential reactivity with an amino acid vs hydrolysis (Figure 3C). The amino acid reactivity increased in the order $N$-Ac-His $<N_{\alpha}$-Ac-Lys $<N$-Ac-Tyr $<N$-Ac-Cys, which is consistent with the nucleophilicity of the amino acids at physiological $\mathrm{pH} .{ }^{39}$ It is important to note the fastest reaction with cysteine, however this affords an unstable thiosulfonate ester adduct that collapses to the corresponding sulfinic acid. ${ }^{33,40}$ Reactions with $N$-Ac-Tyr and $N_{\alpha}$-Ac-Lys afforded the expected sulfonate ester and sulfonamide respectively, with reaction at tyrosine occurring at approximately twice the rate of lysine. $\mathrm{N}$-Ac-His did not form any adduct and only hydrolysis was observed, which occurred at the same rate as previously measured in our hydrolysis studies.

We subsequently profiled the performance of $\mathrm{S}^{\mathrm{VI}}$-F electrophiles in the context of covalent modification of a target protein. Covalent modification of protein targets by electrophilic inhibitors occurs in two steps: i) The inhibitor and target engage in a reversible binding interaction $\left(K_{\mathrm{I}}\right)$, ii) the electrophile reacts irreversibly with the target to form a covalent adduct ( $k$ inact) (Figure 4A). Carbonic anhydrase II (CAII) was selected as a model system to investigate the rate of protein crosslinking by the panel of $\mathrm{S}^{\mathrm{VI}}$-F electrophiles. A recent screen within our group had identified a reactive fragment hit for CAII based on an aryl sulfonamide. The fragment was found to covalently modify a histidine proximal to the $\mathrm{Zn}$ (II) active site.

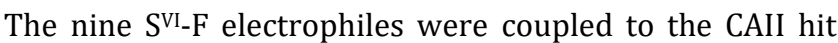
fragment to afford analogues 2a-i (Figure 4B). The rate of CAII modification by fragments $\mathbf{2 a - i}$ was monitored by intact-protein LC-MS (Figure 4C). Rates followed the approximate order of electrophile intrinsic reactivity (Figure 4D), with the two highly reactive sulfonamide-linked fragments $\mathbf{2 a}$ and $\mathbf{2} \mathbf{b}$ displaying the highest rate of modification, while the least reactive fragments $\mathbf{2 g}, \mathbf{2 h}$ and $\mathbf{2 i}$ gave the lowest rates. Interestingly, the remaining fragments $\mathbf{2 c - f}$ displayed modification rates that diverged from intrinsic reactivity. 
A

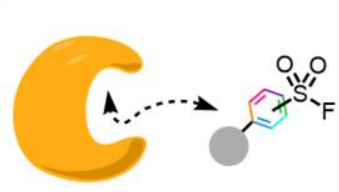

C

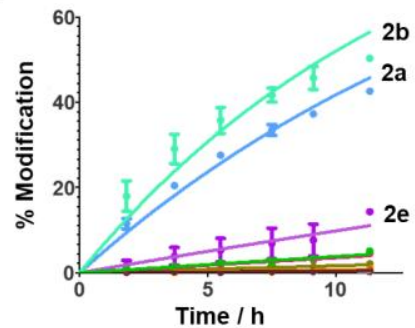

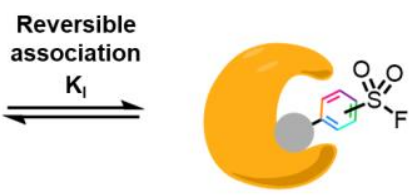

D

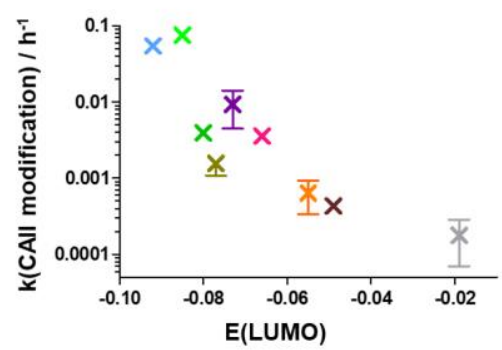

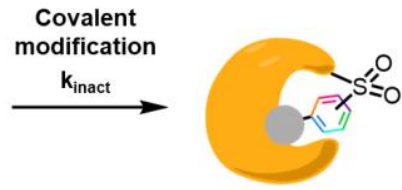

E

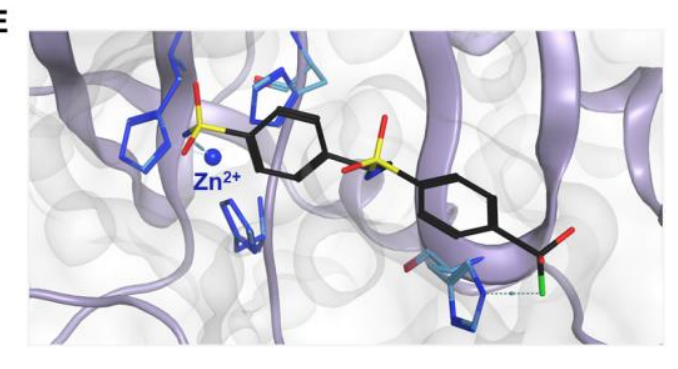

$\mathbf{F}$

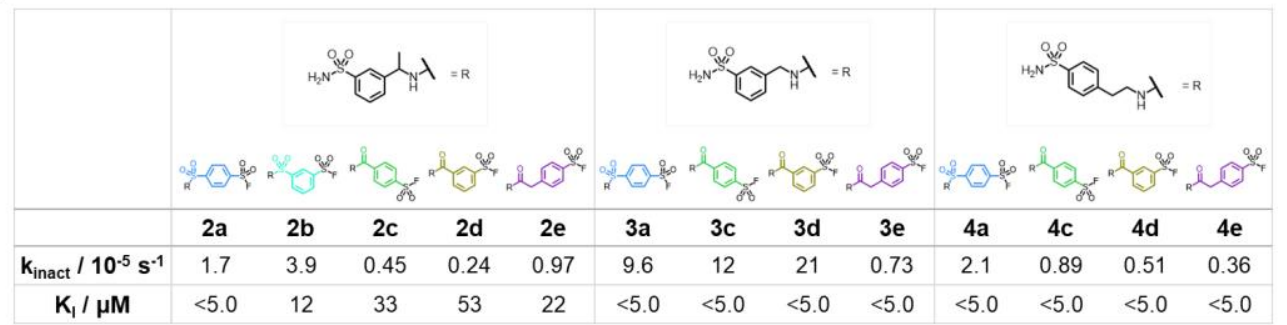

G

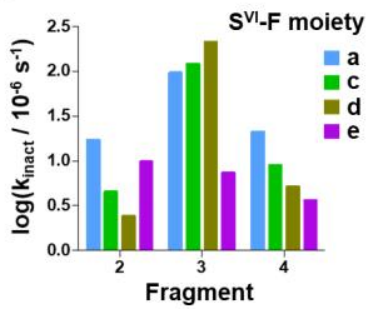

Figure 4. A) The covalent modification of a protein target by a SVI-F electrophilic inhibitor. B) The SVI-F electrophiles (a-i) were substituted onto a CAII hit fragment to afford analogues 2a-i. C) The modification of CAII by fragments 2 a-i over time. D) The correlation between the rate of CAII modification and intrinsic reactivity (LUMO energy). E) An X-ray crystal structure of CAII (PDB: 2VVB) virtually docked with fragment 4 a. F) The measured $k_{\text {inact }}$ and $\mathrm{K}_{\mathrm{I}}$ parameters for the irreversible modification of CAII by SVI-F fragments at $4{ }^{\circ} \mathrm{C}$. G) Measured $k$ inact values showed relatively poor correlation with SvI-F intrinsic reactivity.

$\mathrm{S}^{\mathrm{VI}}$-F electrophiles (a), (c), (d) and (e) were selected for further kinetics studies to deconvolute the contributions of the reversible binding $\left(K_{\mathrm{I}}\right)$ and the covalent reaction ( $k_{\text {inact }}$ ). Two additional CAII binding sulfonamides $\mathbf{3}$ and $\mathbf{4}$ were also coupled to these electrophiles to explore how variation of fragment structure and orientation can affect the kinetic parameters. The rates of covalent modification were measured over a range of concentrations to enable determination of the kinetic parameters, $K_{\mathrm{I}}$ and $k_{\text {inact. }}$.

The reversible affinity of the fragments were typically beyond the limit of the assay $\left(K_{\mathrm{I}}<5 \mu \mathrm{M}\right)$, consistent with previous reports of aryl primary sulfonamides showing submicromolar affinity for CAII (Figure 4E, 4F). ${ }^{41,42}$ The rates of covalent modification ( $k_{\text {inact }}$ ) showed little correlation with the intrinsic reactivity of the $\mathrm{S}^{\mathrm{VI}}$-F electrophile (Figure $4 \mathrm{G}$ ). The results showed some correlation for a given fragment series, e.g. 4a,c,d,e and $\mathbf{2 a}, \mathbf{c}, \mathbf{d}$, however there were several outliers where kinact did not meet the expected value based on the measured intrinsic reactivity, e.g. 2 e and $\mathbf{3 a}, \mathbf{c}, \mathbf{d}$. Interestingly, significant changes in $k_{\text {inact }}$ were observed on variation of the sulfonamide fragment. S ${ }^{\mathrm{VI}}$-F electrophiles (a), (c) and (d) showed much greater reactivity when appended to sulfonamide 3 vs sulfonamides 2 and 4, suggesting that $\mathbf{3}$ positioned the $\mathrm{S}^{\mathrm{VI}} \mathrm{F}$ functionality more optimally for crosslinking.

The intrinsic and protein reactivity profiling highlights the opportunity to tailor $\mathrm{S}^{\mathrm{VI}}$-F electrophiles to span a profound range of reactivities. $\mathrm{S}^{\mathrm{VI}}$-F functionalities that occupy an ideal reactivity space for application to chemical probes will demonstrate sufficient reactivity, while maintaining good aqueous stability at physiological $\mathrm{pH}(>4$ hour aqueous halflife). Among the set of S ${ }^{\mathrm{VI}}$-F electrophiles, $\mathbf{1 d - f}$ fit these criteria with half-lives spanning 10-90 $\mathrm{h}$ and $4-27 \mathrm{~h}$ at $\mathrm{pH} 7$ and 8 , respectively (Figure 3B, 3C). This corresponds to LUMO energies between -0.08 and $-0.06 \mathrm{eV}$, providing guidance for the design of S $\mathrm{VI}^{\mathrm{F}} \mathrm{F}$ functionalities prior to incorporation in chemical tools.

Proteome reactivity. Next, we investigated the ability of these electrophiles to capture proteins in cells using chemoproteomics. Recent work from the Taunton laboratory reported X044 as a $\mathrm{S}^{\mathrm{VI}}$-F probe for kinase proteins. ${ }^{29}$ The $\mathrm{S}^{\mathrm{VI}}$-F electrophile was positioned to react with the conserved catalytic lysine residue in the kinase ATP-binding pocket. We anticipated that this would provide a system to explore the reactivity of our $\mathrm{S}^{\mathrm{VI}}$-F electrophiles against the kinome and wider proteome in live cells. A panel of X044 analogues were synthesised incorporating each of the nine $\mathrm{S}^{\mathrm{VI}}$-F electrophiles: 5a-i (Figure 5A).

An initial assessment of kinase reactivity of probes $\mathbf{5 a - i}$ was performed with recombinant CDK2 protein by intact-protein LC-MS (Figure 5B). Probes 5c and X044 achieved rapid, 


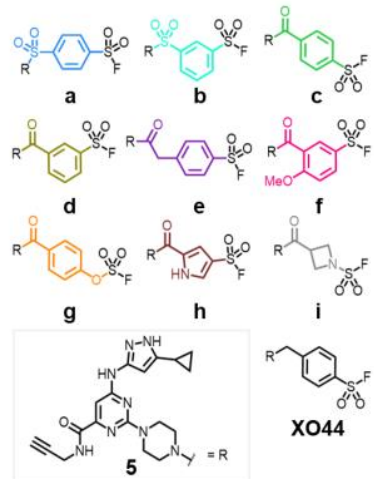

B

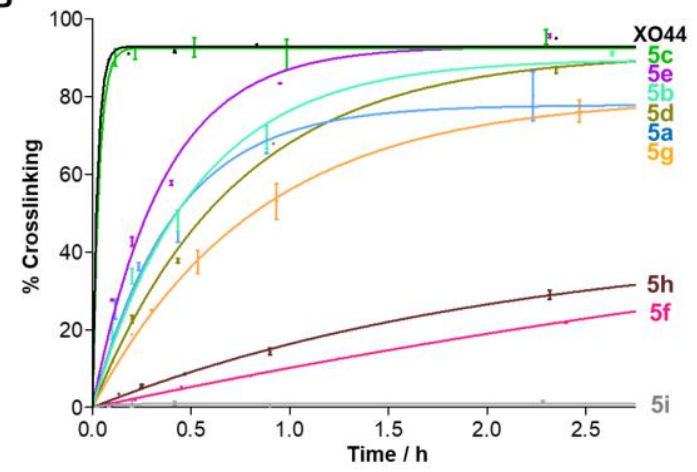

C

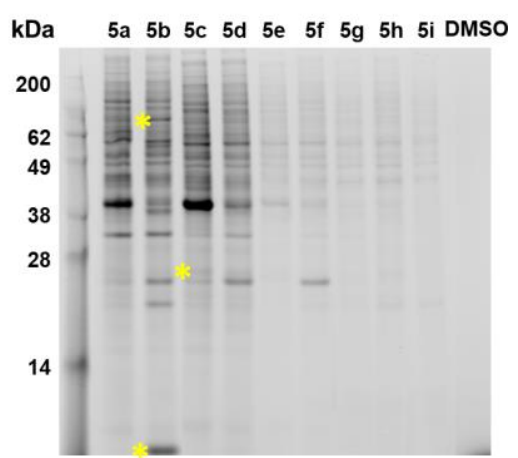

Figure 5. A) The structures of SVI-F kinase probe analogues 5a-i and X044. B) The modification of recombinant CDK2 protein by SVI-F kinase probes over time. C) Gel electrophoresis showing the proteome-wide modification by probes $\mathbf{5 a - i}$ and X044 in cell lysate. Yellow asterisks indicate examples of selective protein modification by probes.

quantitative modification, suggesting that para-substituted SVI-Fs were optimal probe structures for CDK2. The majority of the remaining probes exhibited similar $k_{\text {obs }}$ $\left(0.3-0.8 \times 10^{-3} \mathrm{~s}^{-1}\right)$ despite the variance in intrinsic reactivity, highlighting influences of sterics and orientation on the rates of modification. The conversion by the most reactive probes $\mathbf{5 a}$ and $\mathbf{5 b}$ plateaued at $\sim 75 \%$ and $90 \%$ respectively, potentially reflecting the impact of competing hydrolysis with highly reactive $\mathrm{S}^{\mathrm{VI}}$-F functionalities. The impact of intrinsic reactivity was only apparent for three low reactivity electrophiles (f), (g) and (i) that underwent the slowest modification, while $\mathbf{5 i}$ did not yield any modification of CDK2.

Subsequently, the proteome-wide reactivity of the $\mathrm{S}^{\mathrm{VI}}-\mathrm{F}$ probes was investigated by gel electrophoresis. Probes 5a-i and X044 were incubated with lysate for $2.5 \mathrm{~h}$, followed by click conjugation with Cyanin5.5 azide, gel electrophoresis and fluorescence visualisation (Figure 5C, SI Figure 7). Probes 5a-d exhibited high levels of proteome modification while weak labelling was observed for probes $\mathbf{5 e - i}$, in agreement with the intrinsic reactivity of the SVI-F electrophiles. Several unique bands were observed for various probes, which are indicative of selective target-probe interactions.

Proteome-wide target engagement was analysed in further detail by live cell chemoproteomics. Jurkat T cells were incubated for $1 \mathrm{~h}$ with alkyne-tagged probes $\mathbf{5 a - i}$ and X044 or DMSO vehicle in biological triplicate, before cell lysis and $\mathrm{CuAAC}$ reaction with biotin-PEG3-azide. Labelled proteins were enriched, digested and analysed by LC-MS/MS using label-free quantification and data-independent acquisition (Figure 6A). Enriched kinases were identified by comparison to the DMSO control (two-sample t-test, $\mathrm{q}<0.05$, $\log _{2}$-fold change $>0.58$ ).

In total, probes 5a-i enriched 94 kinases, among which 51 were engaged by three or more probes and 33 were enriched by just one probe (Figure 6B, 6C). An additional 29 kinases were enriched by X044, highlighting kinases where capture perhaps benefits from greater linker flexibility. Conversely, 20 kinases were detected by probes 5a-i that were not enriched by X044. The number of enriched kinases for each probe displayed poor correlation with intrinsic reactivity. Probes 5c and 5g enriched high numbers of kinases (65 and 39) relative to electrophiles with similar intrinsic reactivity ( $\mathbf{5 b}$ and $\mathbf{d}, \mathbf{5} \mathbf{f}$ and $\mathbf{h}$, respectively). The structural similarity of these two probes (para-amide sulfonyl fluoride and fluorosulfate, respectively) points to either reversible recognition and/or the trajectory of the reacting species to the conserved lysine as being key determinants of covalent capture. The impact of SVI-F intrinsic reactivity was only apparent for the low reactivity probes $\mathbf{5 f}, \mathbf{5 h}$ and 5i, which enriched the fewest kinases (Figure 6C).

The coverage of the kinase phylogenetic tree by our probe set revealed high representation of certain sub-groups of kinases, such as the CMGC group (17/34 kinases), and TK group, including ITK, JAK1, SRC and LCK that are of therapeutic relevance. ${ }^{43}$ Other classes were poorly represented, such as the CAMK group (6/31) and CK1 groups (0/10), highlighting opportunities for further probe development (Figure 6D). ${ }^{44}$

Analysis of the number of probes that captured each kinase provided insights into the specificity and SAR of kinase capture. Many proteins were enriched by a number of probes, e.g. CDK1,2,4,5 were enriched by all probes except $\mathbf{5 i}$, which was consistent with our recombinant CDK2 studies (Figure 5B, 6E). Conversely, the three detected PIKK family kinases were all enriched by $\mathbf{5 i}$ (Figure 6E), indicating that sulfamoyl fluorides can perform covalent capture in specific environments. Notably, the tumour suppressor serine/threonine kinase, STK11, was the only kinase enriched by all nine probes. ${ }^{45} \mathrm{~S}^{\mathrm{VI}}$-F orientation appears to influence protein capture, as observed with the enrichment of STK24 by only the three para-substituted $\mathrm{S}^{\mathrm{VI}}$-F electrophiles and DCK enrichment by meta-substituted probes $\mathbf{5 b}, \mathbf{5 d}$ and $\mathbf{5 f}$. Certain enrichment profiles suggested $\mathrm{S}^{\mathrm{VI}}$-F reactivitydriven target modification, where engagement is observed by only the highly reactive probes $\mathbf{5 a - d , ~ e . g . ~ J A K 1 . ~ A d d i t i o n - ~}$ ally, the modification of SRC and LCK by probes $\mathbf{5 c - f}$ may indicate reactivity-dependent modification in combination with poor tolerance for the sulfonamide linkage present in probes $\mathbf{5 a}$ and $\mathbf{5 b}$.

Enrichment analyses were subsequently performed across the remaining proteome to determine the promiscuity of probes (Figure 6F). A total of 559 non-kinases were found 
A

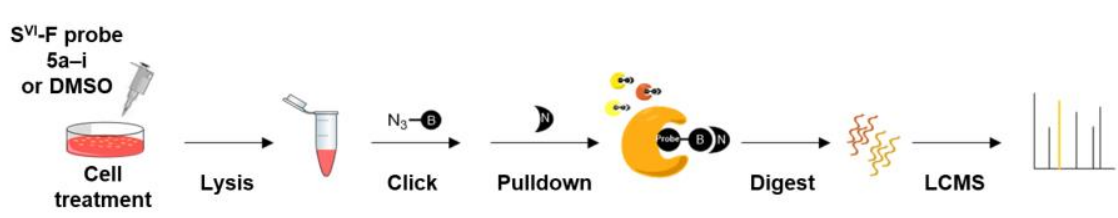

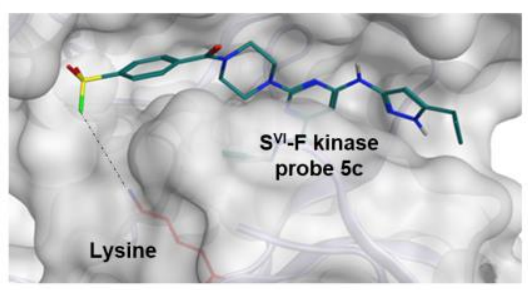

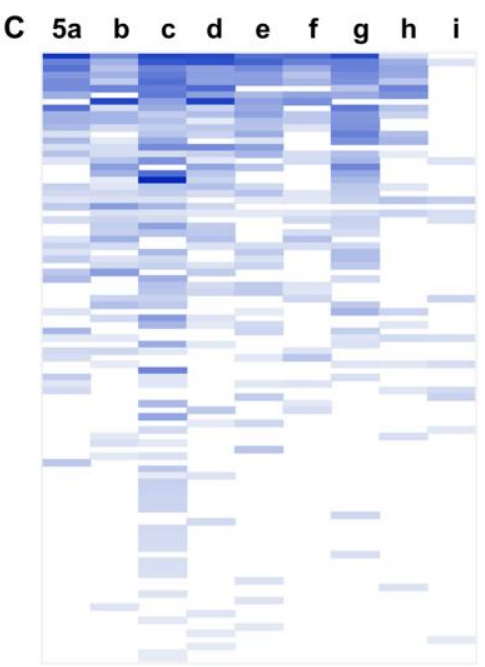

F

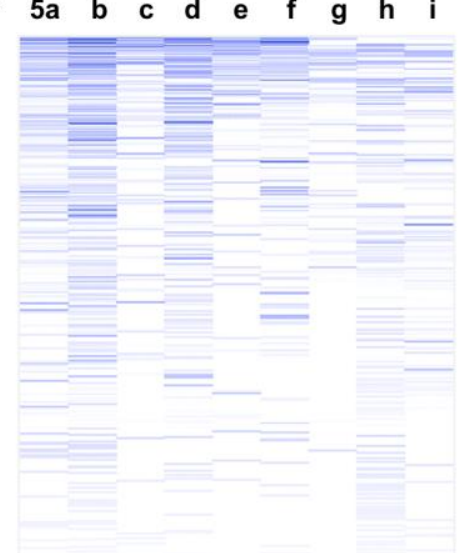

D

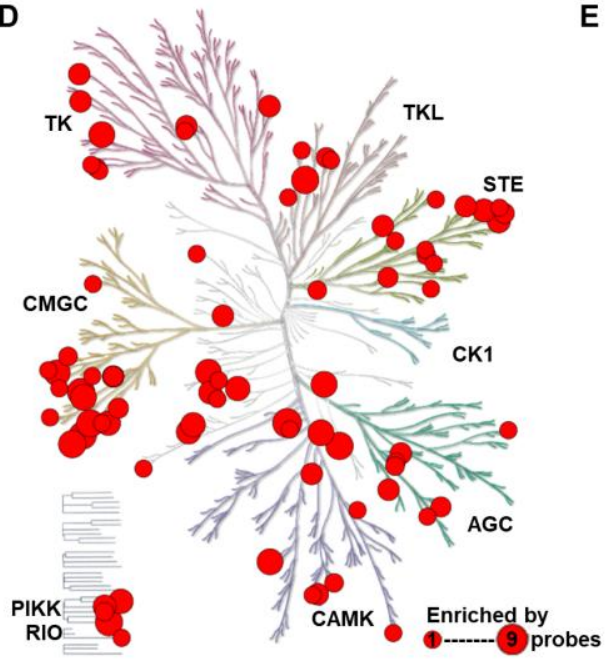

G

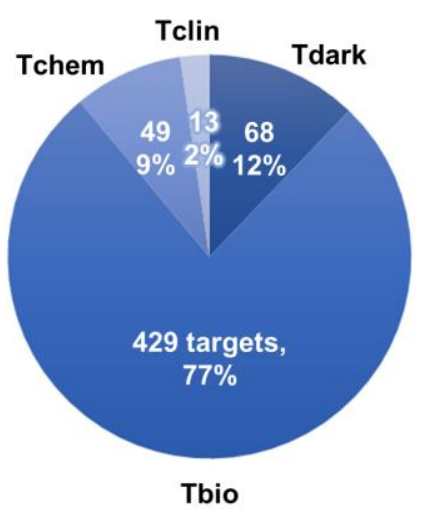

E

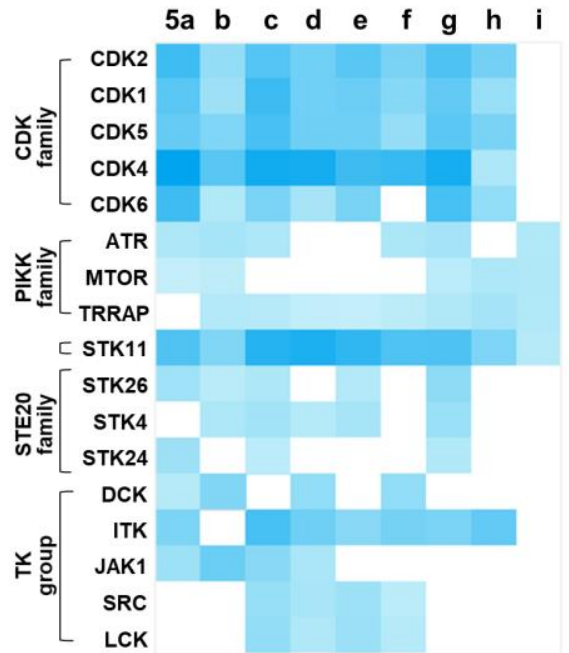

H

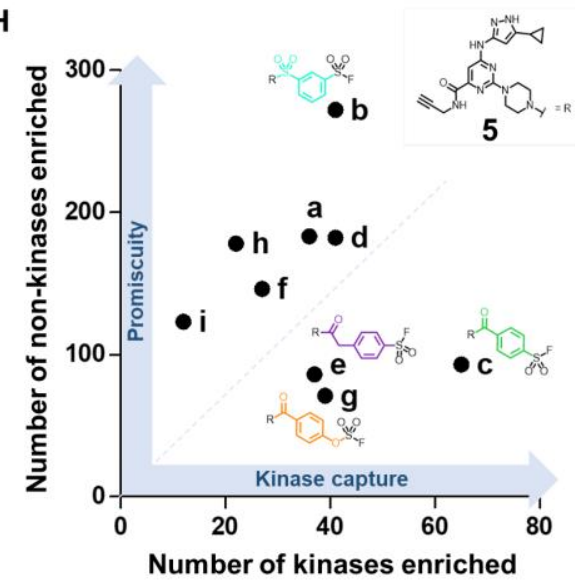

Figure 6. A) The chemoproteomic workflow undertaken to identify proteins modified by probes $\mathbf{5 a - i}$ in live cells. B) X-ray crystal structure of CDK2 (PDB: 6INL) virtually docked with probe 5c. C) A heatmap of the kinases enriched by probes $5 \mathbf{a}-\mathbf{i}\left(\mathrm{q}<0.05, \log _{2}-\right.$ fold $>0.58$ ). The colour scale indicates magnitude of $\log _{2}$-fold change: $0.58-5.0$. D) A phylogenetic kinome tree, showing the number of probes that enriched various kinases. E) A heatmap describing the enrichment of particular protein targets by probes $\mathbf{5 a - i . ~ F ) ~ A ~}$ heatmap of the non-kinases enriched by probes $5 \mathbf{a}-\mathbf{i}\left(\mathrm{q}<0.05, \log _{2}\right.$-fold $\left.>0.58\right)$. The colour scale indicates magnitude of $\log _{2}$-fold change: 0.58-5.0. G) A summary of the target development levels of all enriched proteins. H) The numbers of kinases and nonkinases enriched by each probe.

to be enriched by probes $\mathbf{5 a - i}\left(\mathrm{q}<0.05, \log _{2}\right.$-fold change $>$ 0.58). We assessed the opportunity to expand the liganded proteome using $\mathrm{S}^{\mathrm{VI}}$-F electrophiles by examining the target development level (TDL) of captured proteins (Figure 6G). ${ }^{46}$ Of the enriched proteins, 497 (89\%) were classified as Tdark and Tbio, for which no quality binders are known. Probes 5a-i may help address the knowledge deficit concerning Tdark and Tbio targets. We also compared our enrichment profile with those of six published cysteine-targeting proteomics studies. ${ }^{3,17,47-50}$ It was found that 217 (39\%) non-kinase proteins captured here were not robustly identified across the six Cys-targeting studies $(0 / 6$ or $1 / 6$ studies), demonstrating the potential for $\mathrm{S}^{\mathrm{VI}}$-Fs to contribute to expanding the liganded proteome. Inspection of our enriched proteins identified 12 hydrolases and 11 serine proteases that possess nucleophilic binding site residues, which may be expected to react with SVI-F electrophiles. Further, many protein targets that are traditionally challenging to target were captured, including 21 mRNA splicing factors, 10 ligases, 17 ribosomal proteins, and 13 
transcription factors. Three non-kinases were enriched by all nine probes, including RBMX and ERCC4 that both have therapeutic relevance, while 192 non-kinases (34\%) were modified by three or more probes, highlighting a potential opportunity to develop selective S ${ }^{\mathrm{V}}$-F chemical probes for these proteins. ${ }^{51,52}$ The least reactive probe $\mathbf{5 i}$ modified few proteins, but interestingly, it was the sole probe to modify a set of 20 non-kinases, suggesting the presence of privileged interactions.

Proteome promiscuity showed some correlation with SVI-F intrinsic reactivity, with probes $\mathbf{5 a - e}$ generally enriching more proteins than probes $\mathbf{5 f - i}$ (Figure 6F). The probes appeared to display an inverse relationship between kinome and proteome enrichment whereby probes that labelled large numbers of kinases, e.g. (c) and (g), were not observed to modify other proteins in the proteome (Figure $6 \mathrm{H}$ ). This highlights a competition between kinome vs off-target labelling among the panel, and illustrates that subtle changes in $\mathrm{S}^{\mathrm{VI}}$-F electrophile structure can alter the covalent capture profile.

\section{CONCLUSIONS}

Sulfur(VI) fluorides enable covalent capture of multiple amino acid residues, thus offering profound utility in the development of tools for chemical biology and expansion of the liganded proteome. To fully realize the potential of these 'beyond cysteine' covalent capture approaches, an in-depth understanding of the parameters that determine protein capture are required. The assessments of $S^{\mathrm{VI}}$-F stability, reactivity, protein modification kinetics and chemoproteomic performance have provided insights into how these functionalities can be deployed for the prospective design and application of $\mathrm{S}^{\mathrm{VI}}$-F reactive tools.

The panel of $\mathrm{S}^{\mathrm{VI}}$-Fs studied here displayed a large range of reactivities and stabilities, highlighting that the electrophiles are highly tunable for reaction with a target of interest while minimising aqueous hydrolysis and off-target re-

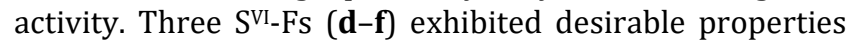
for application in biological systems and provide starting points for the generation of reactive tools. It is anticipated that as ligands are developed with increasing reversible affinity, it will be possible to substitute less reactive $S^{\text {VI-Fs }}$ such as (h) and (i), to enhance selectivity. Furthermore, this work has enabled the prediction of S $\mathrm{SI}^{\mathrm{V}} \mathrm{F}$ reactivity via LUMO energy calculations, providing a valuable method to tune $\mathrm{S}^{\mathrm{VI}}$-F tools and offering a foundation for the design of novel $\mathrm{S}^{\mathrm{VI}}$-F ligands with desirable reactivity.

Studies on protein modification kinetics revealed some correlation between $k_{\text {inact }}$ and $\mathrm{S}^{\mathrm{VI}}$-F intrinsic reactivity, particularly when comparing across a large range of LUMO energies. Where the probes exhibited intermediate intrinsic reactivity (e.g. d-f), the protein kinetics were more nuanced, highlighting the influence of structural and orientational effects on modification rates, such as the trajectory of the electrophile towards the residue, and local protein-electrophile interactions that perturb reactivity. ${ }^{11,53,54}$ For inhibitor optimisation, it will likely be necessary to incorporate multiple different $\mathrm{S}^{\mathrm{V}}$-Fs electrophiles to identify those that form protein interactions that optimise $K_{\mathrm{I}}$ and $k_{\text {inact }}$.
Live cell proteomic profiling of the $\mathrm{S}^{\mathrm{VI}}-\mathrm{F}$ panel linked to a pan-kinase inhibitor indicated that all electrophiles gave a high selectivity toward capture of kinases and good coverage of the kinome. This highlights a tolerance of a broad range of SVI-F electrophiles in chemoproteomic profiling, perhaps facilitated by the use of a potent kinase scaffold. Further studies to explore how this observation varies with less potent compounds will be informative, particularly with respect to the application of $\mathrm{S}^{\mathrm{VI}}$-F fragment based approaches in live cells. ${ }^{55}$

Evaluation of the non-kinome proteins that were enriched identified hundreds of additional targets, including many that have not been liganded to date (categorised as Tdark and Tbio). These probe-protein interactions may provide useful starting points for the development of SVI-F reactive tools. The diversity of protein classes captured highlights the capacity for S ${ }^{\mathrm{VI}}$-Fs to modify a broad scope of the proteome, much of which is not traditionally considered to be tractable.

Together, these results provide confidence that SVI-Fs are highly complementary to cysteine-reactive approaches, enabling translation of the opportunities offered by traditional reactive tools to a broader proportion of the proteome. 


\section{References}

(1) Bunnage, M. E.; Chekler, E. L. P.; Jones, L. H. Target Validation Using Chemical Probes. Nat. Chem. Biol. 201394 2013, 9 (4), 195-199. https://doi.org/10.1038/nchembio.1197.

(2) Hacker, S. M.; Backus, K. M.; Lazear, M. R.; Forli, S.; Correia B. E.; Cravatt, B. F. Global Profiling of Lysine Reactivity and Ligandability in the Human Proteome. Nat. Chem. 2017, 9 (12), 1181-1190. https://doi.org/10.1038/nchem.2826.

(3) Vinogradova, E. V.; Zhang, X.; Remillard, D.; Lazar, D. C.; Suciu, R. M.; Wang, Y.; Bianco, G.; Yamashita, Y.; Crowley, V. M.; Schafroth, M. A.; Yokoyama, M.; Konrad, D. B.; Lum, K. M.; Simon, G. M.; Kemper, E. K.; Lazear, M. R.; Yin, S.; Blewett, M. M.; Dix, M. M.; Nguyen, N.; Shokhirev, M. N.; Chin, E. N.; Lairson, L. L.; Melillo, B.; Schreiber, S. L.; Forli, S.; Teijaro, J. R.; Cravatt, B. F. An Activity-Guided Map of Electrophile-Cysteine Interactions in Primary Human T Cells. Cell 2020, $182 \quad$ (4), 1009-1026. https://doi.org/10.1016/j.cell.2020.07.001.

Teng, M.; Ficarro, S. B.; Yoon, H.; Che, J.; Zhou, J.; Fischer, E. S.; Marto, J. A.; Marto, J. A.; Zhang, T.; Gray, N. S. Rationally Designed Covalent BCL6 Inhibitor That Targets a Tyrosine Residue in the Homodimer Interface. ACS Med. Chem. Lett. 2020, 11 (6), 1269-1273. https://doi.org/10.1021/acsmedchemlett.0c00111.

(5) Sutanto, F.; Konstantinidou, M.; Dömling, A. Covalent Inhibitors: A Rational Approach to Drug Discovery. RSC Med. Chem. 2020, 11 (8), 876-884 https://doi.org/10.1039/D0MD00154F.

(6) Shin, Y.; Jeong, J. W.; Wurz, R. P.; Achanta, P.; Arvedson, T.; Bartberger, M. D.; Campuzano, I. D. G.; Fucini, R.; Hansen, S. K.; Ingersoll, J.; Iwig, J. S.; Lipford, J. R.; Ma, V.; Kopecky, D. J.; McCarter, J.; San Miguel, T.; Mohr, C.; Sabet, S.; Saiki, A. Y.; Sawayama, A.; Sethofer, S.; Tegley, C. M.; Volak, L. P.; Yang, K.; Lanman, B. A.; Erlanson, D. A.; Cee, V. J. Discovery of N(1-Acryloylazetidin-3-Yl)-2-(1 H-Indol-1-Yl)Acetamides as Covalent Inhibitors of KRASG12C. ACS Med. Chem. Lett. 2019, 10

$1302-1308$ https://doi.org/10.1021/acsmedchemlett.9b00258.

(7) Kwiatkowski, N.; Zhang, T.; Rahl, P. B.; Abraham, B. J.; Reddy, J.; Ficarro, S. B.; Dastur, A.; Amzallag, A.; Ramaswamy, S.; Tesar, B.; Jenkins, C. R.; Hannett, N. M.; McMillin, D.; Sanda, T.; Sim, T.; Kim, N. D.; Look, T.; Mitsiades, C.; Weng, A. P.; Brown, J. R.; Benes, C. H.; Marto, J. A.; Young, R. A.; Gray, N. S. Targeting Transcription Regulation in Cancer with a Covalent CDK7 Inhibitor. Nature 2014, 511 (7511), 616. https://doi.org/10.1038/NATURE13393.

(8) Weerapana, E.; Speers, A. E.; Cravatt, B. F. Tandem Orthogonal Proteolysis-Activity-Based Protein Profiling (TOP-ABPP) - a General Method for Mapping Sites of Probe Modification in Proteomes. Nat. Protoc. 200726 2007, 2 (6), 1414-1425. https://doi.org/10.1038/nprot.2007.194.

(9) Brulet, J. W.; Borne, A. L.; Yuan, K.; Libby, A. H.; Hsu, K. L. Liganding Functional Tyrosine Sites on Proteins Using SulfurTriazole Exchange Chemistry. J. Am. Chem. Soc. 2020, 142 (18), 8270-8280. https://doi.org/10.1021/jacs.0c00648.

(10) Grant, E. K.; Fallon, D. J.; Hann, M. M.; Fantom, K. G. M.; Quinn, C.; Zappacosta, F.; Annan, R. S.; Chung, C. W.; Bamborough, P.; Dixon, D. P.; Stacey, P.; House, D.; Patel, V. K.; Tomkinson, N. C. O.; Bush, J. T. PhotoAffinity Bits: A Photoaffinity-Based Fragment Screening Platform for Efficient Identification of Protein Ligands. ChemRxiv 2020, 58, 17322 17327. https://doi.org/10.26434/chemrxiv.12053445.

(11) Johansson, H.; Tsai, Y. C. I.; Fantom, K.; Chung, C. W.; Kümper, S.; Martino, L.; Thomas, D. A.; Eberl, H. C.; Muelbaier, M.; House, D.; Rittinger, K. Fragment-Based Covalent Ligand Screening Enables Rapid Discovery of Inhibitors for the RBR E3 Ubiquitin Ligase HOIP. J. Am. Chem. Soc. 2019, 141 (6), 2703 2712. https://doi.org/10.1021/jacs.8b13193.

(12) Resnick, E.; Bradley, A.; Gan, J.; Douangamath, A.; Krojer, T.; Sethi, R.; Geurink, P. P.; Aimon, A.; Amitai, G.; Bellini, D.; Bennett, J.; Fairhead, M.; Fedorov, O.; Gabizon, R.; Gan, J.; Guo, J.; Plotnikov, A.; Reznik, N.; Ruda, G. F.; Díaz-Sáez, L.; Straub, V. M.; Szommer, T.; Velupillai, S.; Zaidman, D.; Zhang, Y.; Coker, A. R.; Dowson, C. G.; Barr, H. M.; Wang, C.; Huber, K. V. M.; Brennan, P. E.; Ovaa, H.; Von Delft, F.; London, N. Rapid
Covalent-Probe Discovery by Electrophile-Fragment Screening. J. Am. Chem. Soc. 2019, 141 (22), 8951-8968. https://doi.org/10.1021/jacs.9b02822.

(13) Thomas, R. P.; Heap, R. E.; Zappacosta, F.; Grant, E. K.; Pogány, P.; Besley, S.; Fallon, D. J.; Hann, M. M.; House, D.; Tomkinson, N. C. O.; Bush, J. T. A Direct-to-Biology High-Throughput Chemistry Approach to Reactive Fragment Screening. Chem. Sci. 2021, $12 \quad$ (36), 12098-12106. https://doi.org/10.1039/d1sc03551g.

(14) Parker, C. G.; Galmozzi, A.; Wang, Y.; Correia, B. E.; Sasaki, K.; Joslyn, C. M.; Kim, A. S.; Cavallaro, C. L.; Lawrence, R. M.; Johnson, S. R.; Narvaiza, I.; Saez, E.; Cravatt, B. F. Ligand and Target Discovery by Fragment-Based Screening in Human Cells. $\begin{array}{lllll}\text { Cell 2017, } & 168 & \text { (3), }\end{array}$ https://doi.org/10.1016/j.cell.2016.12.029.

(15) Bush, J. T.; Leśniak, R. K.; Yeh, T. L.; Belle, R.; Kramer, H.; Tumber, A.; Chowdhury, R.; Flashman, E.; Mecinović, J.; Schofield, C. J. Small-Molecules That Covalently React with a Human Prolyl Hydroxylase - towards Activity Modulation and Substrate Capture. Chem. Commun. (Camb). 2019, 55 (8), 1020. https://doi.org/10.1039/C8CC07706A.

(16) Mullard, A. Fragment-Based Screening Sees the Light. Nat. Rev. Drug Discov. 2020, 19 (11), 742-743. https://doi.org/10.1038/D41573-020-00181-2.

(17) Backus, K. M.; Correia, B. E.; Lum, K. M.; Forli, S.; Horning, B D.; González-Páez, G. E.; Chatterjee, S.; Lanning, B. R.; Teijaro, J. R.; Olson, A. J.; Wolan, D. W.; Cravatt, B. F. Proteome-Wide Covalent Ligand Discovery in Native Biological Systems. Nature 2016, 534 (7608), 570-574. https://doi.org/10.1038/nature18002. London, N.; Miller, R. M.; Krishnan, S.; Uchida, K.; Irwin, J. J.; Eidam, O.; Gibold, L.; Cimermančič, P.; Bonnet, R.; Shoichet, B. K.; Taunton, J. Covalent Docking of Large Libraries for the Discovery of Chemical Probes. Nat. Chem. Biol. 2014, 10 (12), 1066-1072. https://doi.org/10.1038/nchembio.1666.

(19) Weerapana, E.; Wang, C.; Simon, G. M.; Richter, F.; Khare, S.; Dillon, M. B. D. D.; Bachovchin, D. A.; Mowen, K.; Baker, D.; Cravatt, B. F. Quantitative Reactivity Profiling Predicts Functional Cysteines in Proteomes. Nature 2010, 468 (7325), 790-797. https://doi.org/10.1038/nature09472.

(20) Grant, E. K.; Fallon, D. J.; Eberl, H. C.; Fantom, K. G. M.; Zappacosta, F.; Messenger, C.; Tomkinson, N. C. O.; Bush, J. T. A Photoaffinity Displacement Assay and Probes to Study the Cyclin-Dependent Kinase Family. Angew. Chemie - Int. Ed. 2019, $\quad 58 \quad$ (48), 17322-17327. https://doi.org/10.1002/anie.201906321.

(21) Fallon, D. J.; Lehmann, S.; Chung, C. wa; Phillipou, A.; Eberl, C.; Fantom, K. G. M.; Zappacosta, F.; Patel, V. K.; Bantscheff, M.; Schofield, C. J.; Tomkinson, N. C. O.; Bush, J. T. One-Step Synthesis of Photoaffinity Probes for Live-Cell MS-Based Proteomics. Chem. - A Eur. J. 2021. https://doi.org/10.1002/CHEM.202102036.

(22) Bush, J. T.; Walport, L. J.; McGouran, J. F.; Leung, I. K. H.; Berridge, G.; van Berkel, S. S.; Basak, A.; Kessler, B. M.; Schofield, C. J. The Ugi Four-Component Reaction Enables Expedient Synthesis and Comparison of Photoaffinity Probes. Chem. Sci. 2013, 4 (11), 4115-4120. https://doi.org/10.1039/C3SC51708J.

(23) Dalton, S. E.; Dittus, L.; Thomas, D. A.; Convery, M. A.; Nunes, J.; Bush, J. T.; Evans, J. P.; Werner, T.; Bantscheff, M.; Murphy, J. A.; Campos, S. Selectively Targeting the Kinome-Conserved Lysine of $\mathrm{PI} 3 \mathrm{~K} \delta$ as a General Approach to Covalent Kinase Inhibition. J. Am. Chem. Soc. 2018, 140 (3), 932-939. https://doi.org/10.1021/jacs.7b08979.

(24) Qin, Z.; Zhu, Y.; Xiang, Y. Covalent Inhibition of SARS-CoV-2 RBD-ACE2 Interaction by Aptamers with Multiple Sulfur(VI) Fluoride Exchange Modifications.

(25) Baker, B. R. Tissue-Specific Irreversible Inhibitors of Dihydrofolic Reductase. Acc. Chem. Res. 1969, 2 (5), 129-136. https://doi.org/10.1021/ar50017a001.

(26) Mortenson, D. E.; Brighty, G. J.; Plate, L.; Bare, G.; Chen, W.; Li, S.; Wang, H.; Cravatt, B. F.; Forli, S.; Powers, E. T.; Sharpless, K. B.; Wilson, I. A.; Kelly, J. W. 'inverse Drug Discovery' Strategy to Identify Proteins That Are Targeted by Latent Electrophiles As Exemplified by Aryl Fluorosulfates. $J$. Am. Chem. Soc. 2018, 140 (1), 200-210. 
Brighty, G. J.; Botham, R. C.; Li, S.; Nelson, L.; Mortenson, D E.; Li, G.; Morisseau, C.; Wang, H.; Hammock, B. D.; Sharpless, K. B.; Kelly, J. W. Using Sulfuramidimidoyl Fluorides That Undergo Sulfur(vi) Fluoride Exchange for Inverse Drug Discovery. Nat. Chem. 2020, 12 (10), 906-913. https://doi.org/10.1038/s41557-020-0530-4.

(28) Wan, X.; Yang, T.; Cuesta, A.; Pang, X.; Balius, T. E.; Irwin, J. J.; Shoichet, B. K.; Taunton, J. Discovery of Lysine-Targeted EIF4E Inhibitors through Covalent Docking. J. Am. Chem. Soc. 2020, 142 (11), 4960-4964 https://doi.org/10.1021/JACS.9B10377.

(29) Zhao, Q.; Ouyang, X.; Wan, X.; Gajiwala, K. S.; Kath, J. C.; Jones, L. H.; Burlingame, A. L.; Taunton, J. Broad-Spectrum Kinase Profiling in Live Cells with Lysine-Targeted Sulfonyl Fluoride Probes. J. Am. Chem. Soc. 2017, 139 (2), 680-685. https://doi.org/10.1021/jacs.6b08536.

(30) Zheng, Q.; Woehl, J. L.; Kitamura, S.; Santos-Martins, D.; Smedley, C. J.; Li, G.; Forli, S.; Moses, J. E.; Wolan, D. W.; Barry Sharpless, K. SuFEx-Enabled, Agnostic Discovery of Covalent Inhibitors of Human Neutrophil Elastase. Proc. Natl. Acad. Sci. U. $\quad S . \quad$ A. 2019, $116 \quad$ (38), 18808-18814. https://doi.org/10.1073/pnas.1909972116.

(31) Hett, E. C.; Xu, H.; Geoghegan, K. F.; Gopalsamy, A.; Kyne, R. E.; Menard, C. A.; Narayanan, A.; Parikh, M. D.; Liu, S.; Roberts, L.; Robinson, R. P.; Tones, M. A.; Jones, L. H. Rational Targeting of Active-Site Tyrosine Residues Using Sulfonyl Fluoride Probes. ACS Chem. Biol. 2015, 10 (4), 1094-1098. https://doi.org/10.1021/cb5009475.

(32) Martín-Gago, P.; Olsen, C. A. Arylfluorosulfate-Based Electrophiles for Covalent Protein Labeling: A New Addition to the Arsenal. Angewandte Chemie - International Edition. 2019, pp 957-966. https://doi.org/10.1002/anie.201806037.

(33) Mukherjee, H.; Debreczeni, J.; Breed, J.; Tentarelli, S.; Aquila, B.; Dowling, J. E.; Whitty, A.; Grimster, N. P. A Study of the Reactivity of S(VI)-F Containing Warheads with Nucleophilic Amino-Acid Side Chains under Physiological Conditions. Org. Biomol. Chem. 2017, 15 (45), 9685-9695. https://doi.org/10.1039/c7ob02028g.

(34) Knunyants, I. L.; Sokolski, G. A. Fluorinated B-Sultones. Angew. Chemie Int. Ed. English 1972, 11 (7), 583-595. https://doi.org/10.1002/anie.197205831.

(35) Dewar, M. J. S.; Zoebisch, E. G.; Healy, E. F.; Stewart, J. J. P. Development and Use of Quantum Mechanical Molecular Models. 76. AM1: A New General Purpose Quantum Mechanical Molecular Model. J. Am. Chem. Soc. 2002, 107 (13), 3902-3909. https://doi.org/10.1021/JA00299A024.

(36) Mahmoudi, S.; Dehkordi, M. M.; Asgarshamsi, M. H. Density Functional Theory Studies of the Antioxidants-a Review. J. Mol. Model. $2021 \quad 279$ 2021, $27 \quad$ (9), 1-14. https://doi.org/10.1007/S00894-021-04891-1.

(37) Govindarajan, M.; Karabacak, M.; Suvitha, A.; Periandy, S. FTIR, FT-Raman, Ab Initio, HF and DFT Studies, NBO, HOMOLUMO and Electronic Structure Calculations on 4-Chloro-3Nitrotoluene. Spectrochim. Acta Part A Mol. Biomol. Spectrosc. 2012, 89, 137-148. https://doi.org/10.1016/J.SAA.2011.12.067.

(38) Sicilio, F.; Peterson, M. D. Ratio Errors in Pseudo First Order Reactions. J. Chem. Educ. 1961, 38 (11), 576-577. https://doi.org/10.1021/ed038p576.

(39) Bischoff, R.; Schlüter, H. Amino Acids: Chemistry, Functionality and Selected Non-Enzymatic Post-Translational Modifications. Journal of Proteomics. 2012, pp 2275-2296. https://doi.org/10.1016/j.jprot.2012.01.041.

(40) Mahieu, J. P.; Gosselet, M.; Sebille, B.; Beuzard, Y. Synthesis of New Thiosulfonates and Disulfides from Sulfonyl Chlorides and Thiols. Synth. Commun. 1986, 16 (13), 1709-1722. https://doi.org/10.1080/00397918608056430.

(41) van Der Zouwen, A. J.; Lohse, J.; Wieske, L. H. E.; Hohmann, K. F.; Van Der Vlag, R.; Witte, M. D. An in Situ Combinatorial Methodology to Synthesize and Screen Chemical Probes. Chem. Commun. 2019, 55 (14), 2050-2053. https://doi.org/10.1039/c8cc06991c.

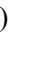

Bonardi, A.; Nocentini, A.; Bua, S.; Combs, J.; Lomelino, C.; Andring, J.; Lucarini, L.; Sgambellone, S.; Masini, E.; Mckenna, R.; Gratteri, P.; Supuran, C. T. Sulfonamide Inhibitors of Human Carbonic Anhydrases Designed through a Three-Tails Approach: Improving Ligand/Isoform Matching and Selectivity of Action. Cite This J. Med. Chem 2020, 63, 7422-7444. https://doi.org/10.1021/acs.jmedchem.0c00733.

Zarrin, A. A.; Bao, K.; Lupardus, P.; Vucic, D. Kinase Inhibition in Autoimmunity and Inflammation. Nat. Rev. Drug Discov. 2020 201 2020, 20 (1), 39-63. https://doi.org/10.1038/s41573-0200082-8.

Metz, K. S.; Deoudes, E. M.; Berginski, M. E.; Jimenez-Ruiz, I.; Aksoy, B. A.; Hammerbacher, J.; Gomez, S. M.; Phanstiel, D. H. Coral: Clear and Customizable Visualization of Human Kinome Data. Cell Syst. 2018, 7 (3), 347-350. https://doi.org/10.1016/j.cels.2018.07.001.

Zhao, R.-X.; Xu, Z.-X. Targeting the LKB1 Tumor Suppressor. Curr. Drug Targets 2014, 15 (1), 32-52. https://doi.org/10.2174/1389450114666140106095811.

Oprea, T. I.; Bologa, C. G.; Brunak, S.; Campbell, A.; Gan, G. N.; Gaulton, A.; Gomez, S. M.; Guha, R.; Hersey, A.; Holmes, J.; Jadhav, A.; Jensen, L. J.; Johnson, G. L.; Karlson, A.; Leach, A. R.; Ma'ayan, A.; Malovannaya, A.; Mani, S.; Mathias, S. L.; McManus, M. T.; Meehan, T. F.; Von Mering, C.; Muthas, D.; Nguyen, D. T.; Overington, J. P.; Papadatos, G.; Qin, J.; Reich, C.; Roth, B. L.; Schürer, S. C.; Simeonov, A.; Sklar, L. A.; Southall, N.; Tomita, S.; Tudose, I.; Ursu, O.; Vidović, D.; Waller, A.; Westergaard, D.; Yang, J. J.; Zahoránszky-Köhalmi, G. Unexplored Therapeutic Opportunities in the Human Genome. Nature Reviews Drug Discovery. 2018, pp 317-332. https://doi.org/10.1038/nrd.2018.14.

Weerapana, E.; Wang, C.; Simon, G. M.; Richter, F.; Khare, S.; Dillon, M. B. D.; Bachovchin, D. A.; Mowen, K.; Baker, D.; Cravatt, B. F. Quantitative Reactivity Profiling Predicts Functional Cysteines in Proteomes. Nat. 20104687325 2010, 468 (7325), 790-795. https://doi.org/10.1038/nature09472.

Senkane, K.; Vinogradova, E. V.; Suciu, R. M.; Crowley, V. M.; Zaro, B. W.; Bradshaw, J. M.; Brameld, K. A.; Cravatt, B. F. The Proteome-Wide Potential for Reversible Covalency at Cysteine. Angew. Chemie - Int. Ed. 2019, 58 (33), 11385-11389. https://doi.org/10.1002/ANIE.201905829.

Counihan, J. L.; Wiggenhorn, A. L.; Anderson, K. E.; Nomura, D. K. Chemoproteomics-Enabled Covalent Ligand Screening Reveals ALDH3A1 as a Lung Cancer Therapy Target. ACS Chem. Biol. 2018, 13 (8), 1970-1977. https://doi.org/10.1021/ACSCHEMBIO.8B00381.

Zanon, P. R. A.; Lewald, L.; Hacker, S. M. Isotopically Labeled Desthiobiotin Azide (IsoDTB) Tags Enable Global Profiling of the Bacterial Cysteinome. ChemRxiv 2019, 59 (7), 2829-2836. https://doi.org/10.26434/chemrxiv.9853445.v1.

Yan, Q.; Zeng, P.; Zhou, X.; Zhao, X.; Chen, R.; Qiao, J.; Feng, L.; Zhu, Z.; Zhang, G.; Chen, C. RBMX Suppresses Tumorigenicity and Progression of Bladder Cancer by Interacting with the HnRNP A1 Protein to Regulate PKM Alternative Splicing. Oncogene 2021, 40 (15), 2635-2650. https://doi.org/10.1038/s41388-021-01666-z.

Manandhar, M.; Boulware, K. S.; Wood, R. D. The ERCC1 and ERCC4 (XPF) Genes and Gene Products. Gene 2015, 569 (2), 153. https://doi.org/10.1016/J.GENE.2015.06.026.

Cuesta, A.; Wan, X.; Burlingame, A. L.; Taunton, J. Ligand Conformational Bias Drives Enantioselective Modification of a Surface-Exposed Lysine on Hsp90. J. Am. Chem. Soc. 2020, 142 (7), 3392-3400. https://doi.org/10.1021/jacs.9b09684.

Pettinger, J.; Carter, M.; Jones, K.; Cheeseman, M. D. Kinetic Optimization of Lysine-Targeting Covalent Inhibitors of HSP72. J. Med. Chem. 2019, 62 (24), 11383-11398. https://doi.org/10.1021/acs.jmedchem.9b01709.

Powell, A.; Bush, J.; House, D.; Rittinger, K.; Boulton, S. Covalent Fragment Screening in Cell-Based Phenotypic Models of Disease: A Collaborative Approach. Drug Target Rev. 2021, pp 60-64. 